\title{
ST Segment Elevation Aggregate
}

National Cancer Institute

\section{Source}

National Cancer Institute. ST Segment Elevation Aggregate. NCI Thesaurus. Code

C117801.

An aggregate ST segment elevation value based on the measurement of ST segment elevation from multiple beats within a single ECG. The method of aggregation, which can vary, is typically a measure of central tendency such as the mean. (CDISC) 